University of Nebraska - Lincoln

DigitalCommons@University of Nebraska - Lincoln

To Improve the Academy

Professional and Organizational Development Network in Higher Education

1996

\title{
What Every Faculty Developer Needs to Know about Learning Groups
}

Larry K. Michaelsen

University of Central Missouri, Imichaelsen@ucmo.edu

L. Dee Fink

Robert H. Black

Follow this and additional works at: https://digitalcommons.unl.edu/podimproveacad

Part of the Higher Education Administration Commons

Michaelsen, Larry K.; Fink, L. Dee; and Black, Robert H., "What Every Faculty Developer Needs to Know about Learning Groups" (1996). To Improve the Academy. 361.

https://digitalcommons.unl.edu/podimproveacad/361

This Article is brought to you for free and open access by the Professional and Organizational Development Network in Higher Education at DigitalCommons@University of Nebraska - Lincoln. It has been accepted for inclusion in To Improve the Academy by an authorized administrator of DigitalCommons@University of Nebraska - Lincoln. 
Michaelsen, L.K., Black, R.H., \& Fink, L. D. (1996). What every faculty developer needs to know about learning groups. In L. Richlin (Ed.), To Improve the Academy, Vol. 15 (pp. 31-57). Stillwater, OK: New Forums Press and the Professional and Organizational Development Network in Higher Education. Key words: Active Learning, Cooperative Learning, Group Formation, Learning Communities.

\section{What Every Faculty \\ Developer Needs to Know about Learning Groups}

\section{Larry K. Michaelsen}

\section{Dee Fink}

University of Oklahoma

\section{Robert H. Black}

Growth Partners

This article advances two related propositions. One is that virtually all of the commonly reported "problems" with learning groups, such as less content coverage, free-riders, and students' feeling that instructors are not teaching unless they are talking, are a natural consequence of they way the groups are being used. The other is that the vast majority of the problems can be prevented by avoiding group assignments that retard the development of effective learning teams and limit student learning. This article will a) examine the underlying causes of the most commonly reported problems with learning groups, b) outline some simple, but effective, strategies for preventing their occurrence in the first place and, c) describe a new tool, the Learning Activity Impact Grid (LAI-Grid), that can be used to ensure that assignments promote both team development and learning. 
In recent years, we have observed two significant trends with respect to the use of learning groups. One is the growing volume of evidence that learning groups can produce a wide range of positive educational outcomes. The other is that an increasing number of faculty members are using learning groups but not experiencing the positive outcomes they had hoped for. Having examined how the groups were used, we are not surprised at the negative outcomes but, as long-time advocates of learning groups, we are very concerned about why the experiments have failed. In many cases, faculty are naively concluding that learning groups are a bad idea for the wrong reasons, such as the characteristics of the students, the nature of the discipline, the size of the classes, etc. Further, our experience at POD and other faculty development conferences suggests that many faculty developers also have a limited understanding of the factors that are key to the success or failure of learning groups. Thus, the primary aims of this article is to examine the underlying causes of the most commonly reported problems with learning groups and to outline some simple, but effective, strategies for preventing their occurrence in the first place.

In spite of the many "failures," we contend that none of the commonly cited problems with learning groups is a necessary evil of the approach. Based on personal experience with over 1,200 learning teams, combined with a long-standing involvement with empirical research on the dynamics of small groups, we are strongly convinced that the vast majority of problems with learning groups are both predictable and nearly totally preventable. In the same way that respiratory problems are a natural consequence of smoking, we contend that the vast majority of reported failures of learning groups are a natural consequence of the way in which the groups are being used. Further, we maintain that most of the difficulty is caused when faculty members use group assignments that make it nearly impossible for groups to develop into effective learning teams and limit student learning.

In the pages that follow, we first discuss some of the beneficial characteristics of and strategies for developing effective learning teams and the way in which group assignments aid or inhibit the team development process. Second, we discuss the characteristics of tasks that promote learning. Finally, we present a new tool, called the 
Learning Activity Impact Grid (LAI-Grid) and outline how it can be used to evaluate the learning value of instructional activities.

\section{Building Effective Learning Teams}

Regardless of the setting, newly-formed/temporary task groups are likely to be stressful for members and very limited in their ability to engage in productive work (Shaw, 81). As a result, giving a group assignment does not guarantee that group members will learn from each other. Groups must first develop to the point that members: a) are willing and able to communicate with one another and b) are motivated to prepare to the point that they have something of substance to communicate.

\section{Characteristics of Effective Learning Teams}

A key to effectively using learning groups is using practices that promote the development of group cohesiveness. This is because group cohesiveness affects both the physical appearance of groups and the interactions between members in ways that profoundly determine whether or not they are likely to learn from each other. The two most important interaction dimensions are the openness of communication between members and their motivation to ensure that the group achieves its goals (see Table 1).

Communication between members. Group/team development occurs through a series of interactions in which members test the extent to which they can trust their peers to take them seriously and treat them fairly. Newly formed/temporary groups are characterized by "small-talk" and members' primary objective is to avoid offending each other. If a member is more frank than expected in expressing disagreement, other members are likely to see him or her as untrustworthy and be doubly cautious about expressing ideas and concerns.

On the other hand, as groups develop into teams, understanding and trust build to the point that members are increasingly able and ready to share information with and provide feedback to each other. The development of a level of cohesiveness that is required for effective learning teams cannot occur at all unless students work together over an extended period of time. In fact, empirical studies 


\begin{tabular}{|c|c|c|c|c|}
\hline \multicolumn{5}{|c|}{ Impact of Team Development on Member Interaction } \\
\hline \multirow{2}{*}{$\begin{array}{c}\text { Team } \\
\text { Development }\end{array}$} & \multirow{2}{*}{$\begin{array}{c}\text { Visual } \\
\text { Appearance }\end{array}$} & \multicolumn{2}{|c|}{$\begin{array}{l}\text { Readiness to Give } \\
\text { Feedback on Peers': }\end{array}$} & \multirow{2}{*}{$\begin{array}{c}\text { Degree of Peer } \\
\text { Influence on } \\
\text { Attendance \& } \\
\text { Preparation } \\
\end{array}$} \\
\hline & & $\begin{array}{c}\text { Concept } \\
\text { Understanding } \\
\end{array}$ & $\begin{array}{c}\text { Interpersonal } \\
\text { Skills } \\
\end{array}$ & \\
\hline $\begin{array}{c}\text { Fully } \\
\text { Developed } \\
\text { Teams }\end{array}$ & & High & High & High \\
\hline $\begin{array}{l}\text { Longer-term } \\
\text { High-cohesive } \\
\text { Task Groups }\end{array}$ & & High & Mixed & Mixed \\
\hline $\begin{array}{l}\text { Longer-term } \\
\text { Low-cohesive } \\
\text { Task Groups }\end{array}$ & 든 & Mixed & Low & Some \\
\hline $\begin{array}{l}\text { Newly-formed } \\
\text { \& Temporary } \\
\text { Task Groups }\end{array}$ & 成了, 到 & Low & Low & Low \\
\hline
\end{tabular}

show that, even under very favorable conditions, groups are heavily dependent on their most competent member until they have worked together in excess of 20-25 hours (Watson, Michaelsen \& Sharp, 1989) and that culturally diverse groups are unable to function as effectively as culturally homogenous groups in less that 35-40 hours (Watson, Kumar \& Michaelsen, 1993).

Members' commitment to ensure group success. In contrast to temporary groups, members of highly cohesive groups are willing to cooperate with others to see that the group succeeds because they honestly believe that it is in their own best interest to do so. As groups develop into teams, members are increasingly willing to commit personal time and effort to ensure that group assignments are completed successfully. As a result, effective learning teams seldom have even minor problems with absenteeism or members being unprepared for group work. This enhances learning in several ways. Students learn through their individual study, from their peers (who also have studied), and from acting in a teaching role in their groups. 


\section{Practices for Building Effective Learning Teams}

Many factors affect group cohesiveness, either facilitating or interfering with the team development process. Most factors are profoundly affected by faculty decisions on course design and classroom management issues. Fortunately, by correctly managing four key variables, instructors can create conditions that eliminate the vast majority of the commonly cited problems. These variables are: a) physical proximity of group members; b) level of interaction required by the group task; c) availability of immediate and unambiguous external comparison/feedback on group performance, and d) the consequences that are associated with group work (see Figure 1).

\section{Figure \#1 \\ Impact of Task rharacteristics on Team Development}

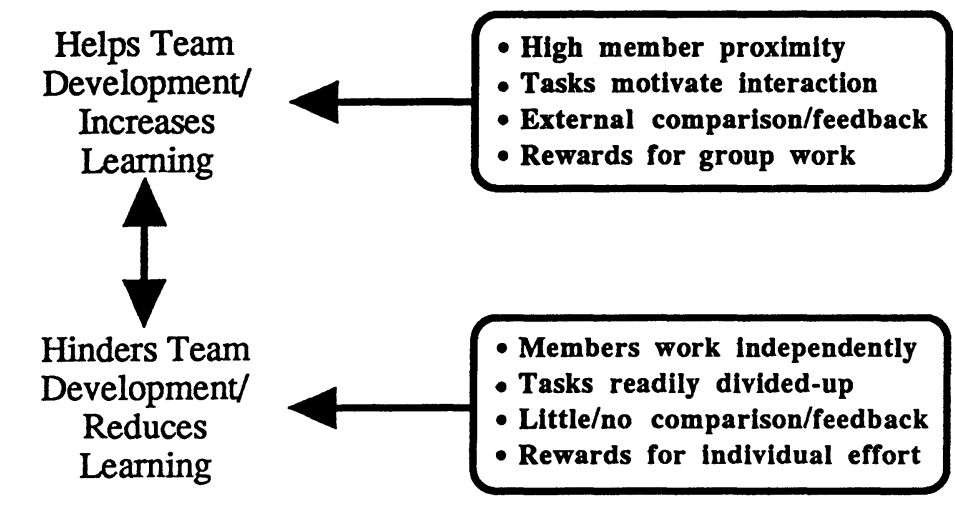

Promoting proximity between members. The degree to which a group becomes cohesive is directly related to the extent to which members do things together. If members don't interact, groups simply will not become cohesive. Being in close physical proximity allows group members to begin the team development process by acquiring a set of common experiences. As a result, we strongly recommend 
using in-class group work and avoiding assignments that require students to do most of their group work on their own.

Our experience strongly suggests that requiring groups to do their work outside of class creates an overwhelmingly powerful barrier to the development of group cohesiveness. In most cases, the "cost" of meeting outside of class is so great that students will meet only long enough to divide up the work so that they can independently complete the components of the assignment. As a result, they produce a group product in name only and, whatever cohesiveness was developed during the initial meeting is usually offset by the worry about whether or not other members will actually do their part.

Although students, particularly the better ones, sometimes complain about having to "carry the deadwood," instructors often rationalize that the assignments are working pretty well because the group products are generally acceptable and sometimes even quite good. Unfortunately, however, the complaints that are voiced are only the tip of the iceberg. Many students who feel like they are being taken advantage of don't complain because faculty members might see them as a whiner, not a team player, just making excuses, etc. Nonetheless those students resent group work in general. Further, outside-class group assignments occasionally produce disputes that are so intense and bitter that they have to be resolved through an academic appeal or some other judicial process. (see Fiechtner \& Davis, 1985).

Assigning tasks that stimulate high levels of group interaction. Groups only become cohesive when they have one or more common goals. Giving a group assignment generally provides members with a common goal. In spite of that, the net impact of poorly designed group assignments can be overwhelmingly negative. The critical variable is the degree to which the activities involved in completing the assignment require a high volume and intensity of group interaction.

Although a number of different types of tasks can increase group cohesiveness, a highly reliable rule of thumb is that assignments will facilitate team development when they require members to make a decision with respect to a complex set of data. Team development occurs because the best way (and probably the only rational way) to successfully complete the task is through a discussion by the entire 
group. As a result, everyone has both the opportunity and an incentive to be directly involved in completing the task.

On the other hand, assignments that can be completed by independent individual work have a powerful, negative influence on team development. When the rational way to complete the task appears to be to delegate the work to individual members, that is exactly what students will do. This commonly occurs in two situations. One situation is when assignments are too easy and group interaction is not needed. In this case, one member will simply act on behalf of the group. The other situation occurs when the task requires a great deal of writing. Since writing is inherently an individual activity, the only real group activity will be deciding how to divide up the work. When group members work independently, cohesiveness is reduced for at least two reasons: some members feel they are having to do more than their fair share (and in most cases, they probably are correct) and the top students are likely to resent having to choose between carrying their less-able or less-motivated peers or risk getting a low grade.

Providing external [meaningful] performance comparison. The single most powerful force for the development of group cohesiveness is the presence of an outside influence that is perceived to be threatening to member goals and/or the well-being of the group. Differences between members become less important as they pull together to protect themselves and/or their public image. As a result, providing performance data that allow comparisons with other groups is a very powerful tool for increasing group cohesiveness.

Some assignments are clearly better than others at providing such comparisons. In general, assignments promote team development to the extent they provide unambiguous performance feedback, that is accompanied by explicit data on the performance of comparable groups. Further, the more immediate the feedback, the greater its value to both learning and group cohesiveness. By contrast, assignments are likely to be major barriers to team development if they force groups to do the majority of their work in the absence of feedback. When groups have no way of knowing how they are doing (such as when they are asked to produce some sort of a complex product like a group paper), members are likely to experience a great deal of stress in working with each other. For example, differences in members' work 
styles often produce a great deal of tension in the group. Members who have a strong preference for a systematic and orderly approach and have time to work on the project often become so anxious that they alienate their peers who either have different time pressures or who feel they do better work when they are faced with a performance deadline.

Rewarding group success. Unless the grading system contains significant rewards for group performance, effective learning teams are not likely to develop for two reasons. First, although we often wish that students would complete assignments simply because of a love of learning, many students will invest their time and effort where they think there will be a payoff, even though doing so will limit both cohesiveness and the effectiveness of their group. In most situations, expecting students to invest a significant amount of time and energy on non-graded group work is clearly asking them to behave irrationally. Second, in the absence of rewards for group performance, team development will be blocked if students find themselves competing with other members of their own group.

\section{Lessons From Disasters}

One evidence of the importance of using assignments that build teams is what happens when instructors use assignments that inhibit team development. Although it doesn't happen very often, students' experience with poorly designed group assignments can turn out to be a nightmare for everyone involved. The good news is that every disaster we know of occurred when the instructor violated the first three prescriptions for assignments that promote the development of effective learning teams. First, there was little or no in-class group work. Second, students divided up the task and worked independently because it was the only rational way to produce a lengthy written document. Third, feedback (which was negative) was delayed until the entire task had been completed. Further, since the document was a group product in name only, the fact that it had an impact on students' grades turned the positive impact of having a group goal into a negative. When this happens, students are truly victims of poor choices 
by the instructor and, if they are angry enough to take action, their only recourse is to challenge the instructor and/or the academic institution.

\section{Assignments that Promote Learning}

The extent to which group assignments produce learning is a function of several factors. Some have to do with the learners; for instance, their existing knowledge base and the way in which knowledge is stored in their minds. Others have to do with the nature of the assignments; for example, the degree to which they require active involvement and the extent to which they provide immediate and unambiguous feedback on the learner's understudying.

\section{How We Learn}

On the surface, what we know would seem to be the sum total of the information to which we have been exposed. The act of taking in information is, however, only part of the learning process (Bruning, Schraw \& Ronning, 1994). Information that is taken in and stored in short-term memory decays very rapidly. Thus, from a practical standpoint, what we know is more a function of our ability to retrieve and use the information than simply the sum total of the information that we have taken in. The nature of these and other cognitive processes also have important implications for the design of effective learning activities (see Bruning, Schraw \& Ronning, 1994).

Our ability to learn is profoundly affected by both information to which we have previously been exposed and the way this information is stored in our long-term memory. Most importantly, our capability to learn is enhanced if our long-term memory contains hypothesized knowledge structures, called schemata, that contain elements of related information and guidelines for gathering new information (Anderson, 1993; Mandler, 1984; Bruning, Schraw \& Ronning, 1994). Although we can temporarily store information through a process called maintenance rehearsal (McKeown \& Curtiss, 1987), these schemata enhance our ability to incorporate information into and retrieve information from long-term memory (see Figure 2). This is because they provide hooks that help us establish links between new information that is related to what we already know and between the 
individual components of our existing schemata. In addition, schemata provide a backdrop that helps us to recognize what we don't know, information that doesn't fit into our schemata

What we know, then, is largely a function of the number, complexity and inter-connectedness of the schemata in our long-term memory and, for practical purposes, consists of the information that we are able to retrieve and use. Significant learning has taken place when we increase the amount of information we are able to retrieve and use and usually occurs when new information motivates us to add to existing schemata, establish new schemata or, establish new links within or between existing schemata.

If a learning activity exposes us to new information that neatly connects to a hook in one of our schemata, then it is simply attached to the appropriate link. If new information appears to conflict with existing schemata, the learning process takes a very different, but even more beneficial, course. Initially, we will search through our longterm memory to review the linkages upon which the apparent conflict is based. If this review confirms the existence of a conflict, we will be in a state of discomfort until we find a harmonious accommodation. If none is found and the information's credibility is sustained, we are motivated to eliminate the conflict by modifying and/or adding to existing schemata. This memory retrieval and examination process, called elaborative rehearsal (see Craik \& Lockhart, 1986), facilitates learning because each stage has a positive impact on students' longterm memory. As a result, the greater the extent to which an assignment exposes students to credible information that conflicts with their existing schemata, the greater its impact on their long-term memory.

Increasing the amount of information stored in students' longterm memory is only one of our challenges as educators. Even though information is stored in long-term memory, students may not be able to use it in solving problems. In the same way that moving information from short-term to long-term memory primarily occurs as we link it to existing schemata, developing the ability to use information requires establishing links between the information and a problem to be solved (see Figure 2). These links are developed through a cycle in which the learner acts (for example, uses a mathematical formula to 
solve an end-of-chapter problem) and receives feedback on his or her actions.

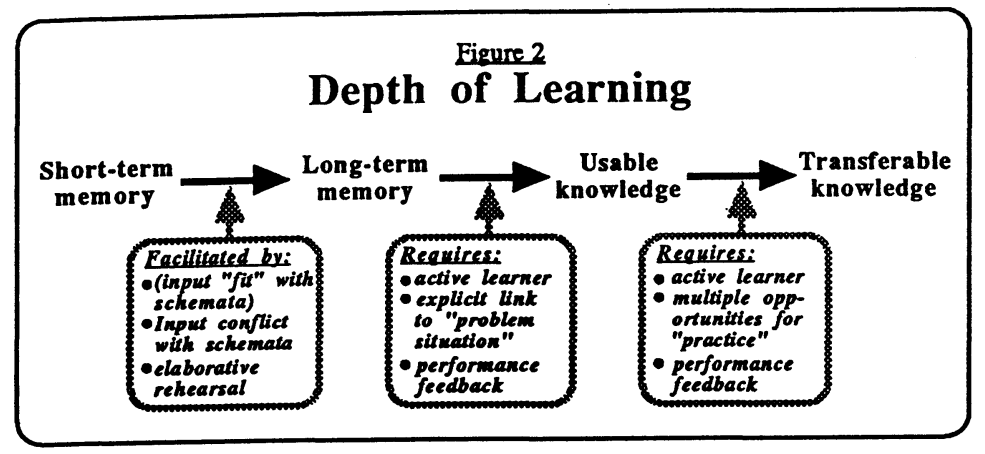

The processes through which we develop the ability to transfer knowledge, to use the information to solve problems with which we have had no previous experience, is even more demanding. This ability to transfer knowledge, simply stated, requires practice (see Figure 2). The more numerous and varied the situations in which we use information in the context of an action-feedback cycle, the greater the likelihood that we can use it to solve new problems (Norman \& Schmidt, 1992; Bruning, Schraw \& Ronning, 1994).

\section{Assignments that Promote Depth of Learning}

Regardless of location on the depth of learning continuum, however, the effectiveness of learning activities is enhanced when learning tasks expose students to information that exposes flaws in their existing schemata. Further, the greater the clarity of the flaws, the greater is the intensity and persistence of elaborative rehearsal. In addition, the depth of the learning is enhanced by activities that require an active response from the learner. As a result, highly effective learning activities: a) expose learners to information that clearly conflicts with their existing schemata; b) require learners to act (typically make a choice) based on their understanding; and c) expose the learners to feedback on their actions and/or choices.

Some activities are clearly better than others for developing students' long-term memory. For example, lectures by themselves are 
unlikely to have more than a minimal effect on students' ability to retrieve information from long-term memory for at least two reasons. One is that, during lectures, students are typically busy taking notes and, as a result, are unable to engage in elaborative rehearsal. The other reason is that the fear of missing something important generally overwhelms students' urge to ponder the implications of what is being said along the way. Thus, unless instructors enrich their lectures by providing opportunities and interspersing their lectures with activities that foster elaborative rehearsal and feedback, students can even get A's without thinking enough to develop their long-term memory (Bonwell \& Eisen, 1991). By contrast, if tests are integrated as part of the instructional process, they are a highly effective learning activity because they invariably stimulate elaborative rehearsal (Bloom, Madaus \& Hastings, 1981; Nungster \& Duchastel, 1982). See Figure 3.

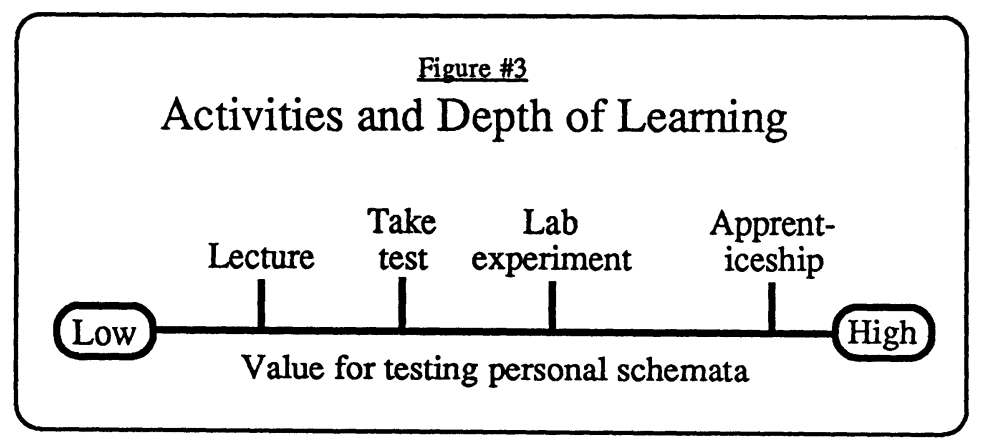

Activities that are appropriate for developing students' knowledge use and transfer skills can range from a single assignment to a comprehensive and extended student/mentor relationship in which a student works under the direct supervision of a subject-matter expert. The effectiveness of activities for developing students' knowledge use and transfer skills is greatest when they a) provide students with multiple cues and sources of data, including data from their own memory that had not previously been linked to the new information; b) ensure that students will either actively work with an existing schema or form a new one; c) provide practice using concepts in a different setting and, d) allow students to receive feedback on their 
performance (Glover, Ronning \& Bruning, 1990). Further, the more iterations of the cycle of observing, analyzing, acting, and receiving feedback, the greater the depth of learning.

\section{Providing Feedback}

Because feedback plays such a pivotal role in developing students' higher-level cognitive skills many faculty feel that they are faced with a dilemma in their teaching role. On one hand, they would like to go beyond simply dispensing information and focus their teaching on developing students' ability to use their knowledge in productive ways. On the other hand, they feel overwhelmed by the personal cost of providing the immediate and high quality feedback needed for the development of students' higher-level cognitive skills. Further, as long as they see themselves as the only (or even the primary) source of feedback, they are absolutely correct. It is clearly impractical for faculty to personally provide the high-quality feedback that is needed for more than a very limited number of students to develop the ability to function effectively in their chosen field of study. Thus, even though most faculty would like to do more, many feel that they have to settle for the far less ambitious, and less satisfying, goal of covering content.

In our judgment, this perceived dilemma is based on a false premise that ignores the tremendous potential that is inherent in the students themselves. Effective learning teams naturally provide a feedback-rich learning environment that, in some ways, is superior to many mentor-apprentice relationships. As groups move along the team development process they increasingly provide a source of motivation for members to prepare for and attend class and take responsibility for each others' learning (Watson, Michaelsen \& Sharp, 1991). In fact, some have argued that the use of learning groups may be the only way to develop students' higher level cognitive skills in large classes (Kurfiss, 1989). 


\section{The Learning Activity Impact Grid - A Powerful Tool for Increasing the Effectiveness of Learning Group Assignments}

Regardless of its primary intent, every learning activity affects learning in two very different ways. First, the specific characteristics of the activity determine the depth of learning that can be achieved by its use. Second, each activity inherently fosters, or inhibits, the peer interactions that have a major impact on team development.

In an attempt to depict the combined impact of these two variables, we have created what we call the Learning Activity Impact Grid (LAI-Grid). An activity's impact with respect to Depth of Learning is portrayed on a scale ranging from 1 (Short-term memory) to 10 (Transferable knowledge). The activity's impact on Team Development is also portrayed on a scale ranging from 1 (Prevents team development) to 10 (Promotes team development). See Figure 4.

\section{Eigure 4 \\ Learning Activity Impact Grid}

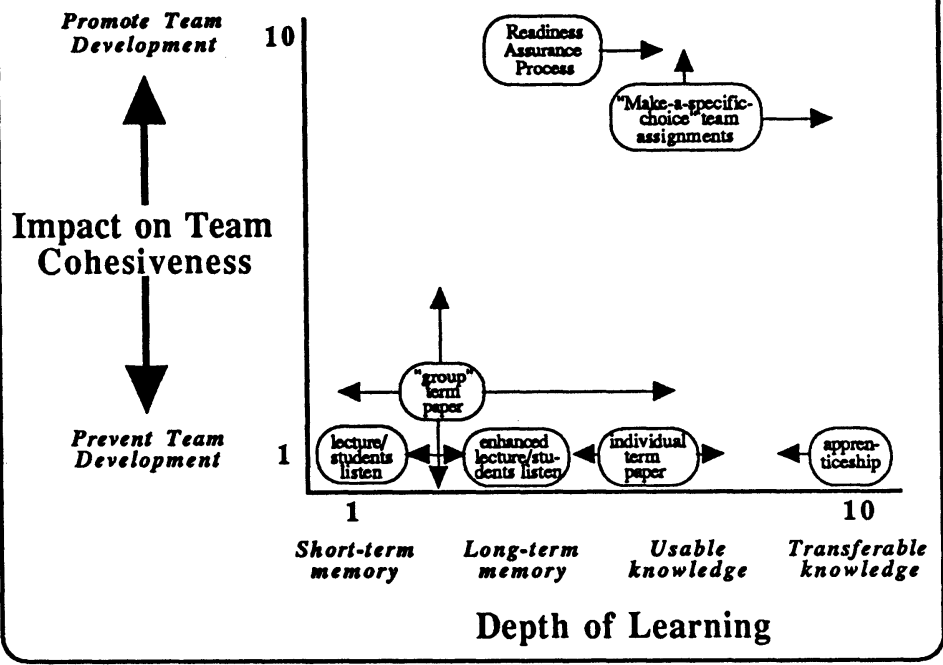


Because of the tremendous potential for positive peer influence and feedback in many aspects of the learning process, we strongly believe that the higher an activity scores on both dimensions, the greater its impact on learning. As a result, we use the sum of the scores on these two dimensions to compute a Learning Value Score (LVS) to represent the potential impact of any given assignment on long-term learning outcomes.

\section{Assessing the Value of Lectures}

Although the impact of any activity on the two dimensions is assessed individually, we recommend examining Depth of Learning prior to assessing Team Development. While teams can facilitate the learning process, the ultimate objective of any activity is increasing learning.

Lectures and learning depth. The positive side of lectures, particularly if they are well done, is that they can be used to expose students to the course content. Further, by enhancing lectures with such things as enthusiastic delivery, connecting the key ideas to familiar examples, and using graphic demonstrations, instructors can engage many students in elaborative rehearsal. To the extent to which this occurs, the key ideas are likely to be linked to schemata in students' long-term memory. On the other hand, lectures are limited in two ways. The first way is that lectures are not an effective means for developing students' higher-order cognitive skills. The ability to use and/or transfer knowledge to new situations requires students (not the instructor) to act and receive feedback on their actions. Given this limitation, lectures would score somewhere between 1 and 3+ on the Depth of Learning scale (see "lecture" and "enriched lecture" on Figure 5).

Lectures and team development. The other limitation of lectures is that they limit team development and, by so doing, preclude peers from assisting the instructor in providing feedback. When the instructor is talking, common courtesy prevents the kind of interpersonal interaction that would foster the development of cohesive student groups. As a result, lectures would score a 1 on the Team Development 
dimension of the LAI-Grid and the overall LVS of lectures would range from $2+$ to $5+$.

\section{Assessing the Value of the Readiness Assurance Process}

Although, the primary means by which students are exposed to course content is through lectures, a number of alternatives have been proposed (Bloom, Hastings \& Madaus, 1983; Cottell, Millis \& Engrave, 1995). One of the most promising is part of an instructional activity sequence (see Figure 5) used in Team Learning (Michaelsen, 1992; Michaelsen, Fink \& Watson, 1994; Michaelsen \& Black, 1994). In most cases, this approach called the Readiness Assurance Process, allows instructors to cover the same amount of material in less than a third of the time previously devoted to lectures.

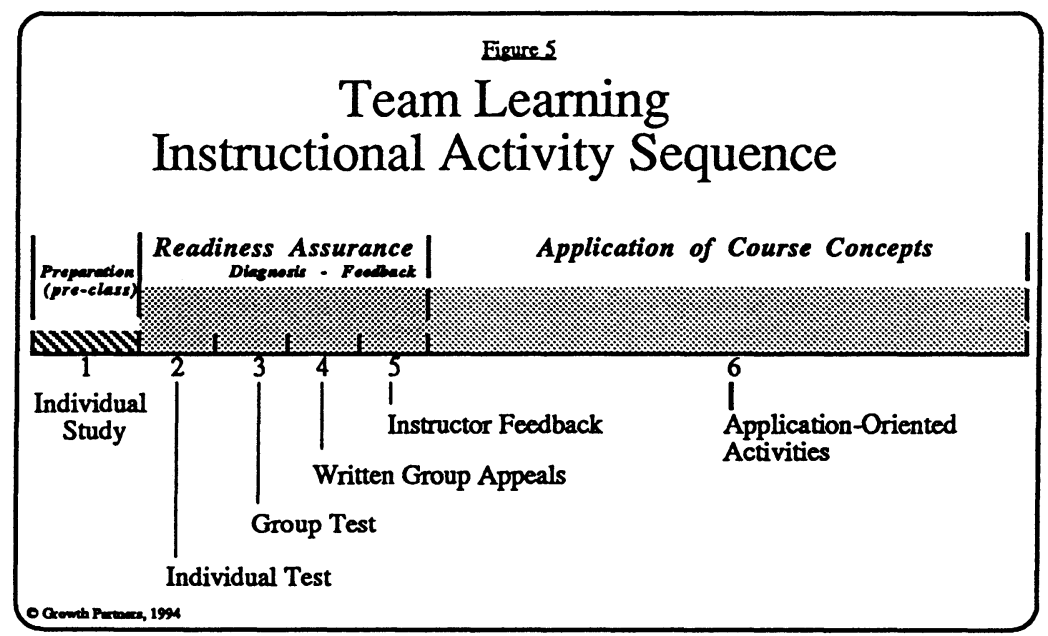

Readiness Assurance Process and Depth of Learning. The Readiness Assurance Process is used to introduce each major instructional unit and to ensure that students are intellectually prepared for assignments that are designed to build their higher level cognitive skills. This process allows instructors to virtually eliminate time that is often wasted in covering material that students could learn on their own. These time savings occur because the instructor's input occurs 
after: a) students have studied the material; b) taken an individual test focused on key concepts from the reading assignment; c) re-taken the same test as a member of a learning team, and d) completed a focused restudy of the most difficult concepts (steps 2-5 in the instructional activity sequence on Figure 5). Further, students encounter new data that test their understanding of key concepts at least five different times and in five very different ways (see Figure 6).

\section{Eigure 6 \\ Readiness Assurance Process}

1) Assigned Readings. In most instances, the students are initially exposed to concepts through assigned readings.

2) Individual Test. Additional exposure during the individ-ual test helps reinforce students' memory of what they learned during their individual study (for a discussion of the positive effects of testing on retention see Nungester \& Duchastel, 1982).

3) Group Test. During group tests, students orally elaborate the reasons for their answer choices. As a result, they are exposed to peer input that aids in strengthening and/or modifying their schemata related to key course concepts. In addition, they gain from acting in a teaching role (for a discussion of the cognitive benefits of teaching see Bargh \& Schul, 80; Slavin \& Karweit, 81).

4) Appeals. Students are then given the opportunity to restore credit for questions missed on the group test by making a successful written appeal. As a result, they are highly motivated to engage in a focused restudy that often clarifies their understanding of particularly troublesome concepts.

5) Oral Instructor Feedback. Steps 1-4 informs the instructor of students' level of concept understanding. In step 5, he or she provides input (i.e., focused lectures) that are specifically aimed at resolving misunderstand-ings that remain after the appeals have been completed.

The Readiness Assurance Process promotes a sound student understanding of fundamental course concepts because learners are intensely involved in a variety of learning activities. For the most part, however, the impact of the Readiness Assurance Process is limited to ensuring that the main ideas are in students' long term memory. A modest and positive exception occurs when carefully designed questions on the Readiness Assurance Test prompt students to provide examples from their personal experience that link course concepts to 
events and/or concepts outside those under study. As a result, the Readiness Assurance Process would generally be a 3+ on the Depth of Learning dimension of the LAI-Grid and clearly is not an activity that could ever score above a 5 or 6 (see Figure 4).

The Readiness Assurance Process and Team Development. Although assuring that students master course concepts in far less time than required for lectures is important, we strongly feel that the greatest value of the Readiness Assurance Process is its effect on team development. In fact, this process is the single most powerful team development activity we are aware of. It clearly meets each of the four criteria that promote team development: students work face-to-face, engage in a high level of interaction, are exposed to immediate and unambiguous feedback at several points in time and, receive both intrinsic and extrinsic rewards for successful team performance. Further, in contrast to traditional lectures, cohesiveness is increased during the final stage of the process when the instructor is presenting information. Groups become more cohesive because, unlike lectures, the content of the instructors' comments is determined by the results of the Readiness Assessment Tests and is specifically aimed at providing useful feedback to the teams. As a result, we would rate the Readiness Assurance Process a 10 on the Team Development and an overall LVS of $13+$ on the LAI-Grid (see Figure 4).

The Readiness Assurance Process in Perspective. Although the potential impact of the Readiness Assurance Process on students' ability to either use or transfer knowledge is limited, it is still an extremely valuable teaching activity because it creates a feedback-rich learning environment. The process builds both the intellectual competence of team members and their ability to work together to solve difficult problems. Over time, team members develop both the ability and the willingness to provide high quality feedback to one another (see Table 1). This is an invaluable tool for instructors because it dramatically reduces the burden of providing feedback to individual students. As a result, the Readiness Assurance Process provides a practical way of ensuring that, even in large classes, students are exposed to a high volume of immediate feedback that, in some ways, is actually better than having a one-on-one relationship between students and instructors (e.g., Vygotsky, 78). 


\section{Assessing the Value of Individual vs. Group Term}

Papers

One of the most valuable functions of the LAI-Grid is that it provides a conceptual framework for assessing the impact of variations of the same basic type of assignment. For example, the learning value of a term paper varies significantly depending upon whether the paper is to be written by students working independently or by students working in a group.

Individual term papers. Although providing feedback is potentially problematic in terms of cost and timing, having students write an individual term paper is an excellent way to increase their long-term memory with respect to an important set of concepts. The act of preparing to express thoughts in writing generally stimulates elaborative rehearsal. Further, if the focus of the assignment requires students to relate the concepts to something else, a term paper is also effective at building students' knowledge-use skills (thus the Depth of Learning score of $3+7$ ). See Figure 4 . In either case, the benefit of the assignment is that it forces students to research a subject and develop a schemata that accommodates the related ideas they have discovered. On the other hand, individual term papers seldom stimulate interaction among peers. As a result, the assignment would receive a score of 1 on Team Development and an overall LVS of 4+-7.

Group term papers. Although individual term papers are an excellent way to increase students' Depth of Learning, the impact of the same assignment, when given to groups, is likely to be much lower. Because writing is inherently an individual activity, groups are likely to use one of two counterproductive strategies to complete the assignment. The majority of groups will approach the problem in the way they think will allow them to get a good grade with a modest level of effort and a minimum of risk. As a result, they will typically divide up the work and assign each member to write the part of the paper that he or she already knows the most about. Although the pieces typically vary in quality and the papers tend to be somewhat disjointed, the overall product is often good enough to satisfy the students' concern about grades and inspire hope on the part of the instructor. Unfortunately, however, there is very little discussion after the initial division 
of labor. As a result, students' exposure to concepts outside of their area of specialization is so cursory that the impact on their long-term memory is minimal. Alternatively, group members decide to complete the assignment by having each member do some research in one area (also in a way that requires the least individual work) and delegate the actual writing to one person. This usually improves the flow of the paper but has mixed effects on students' learning. The writer's Depth of Knowledge score is typically quite high, but other members engage in even less elaborative rehearsal than if they had to do some writing. Their role is reduced to gathering and passing-on information. Thus, irrespective of how the work is done, the overall Learning Depth score is likely to be lower (around 3) for group papers than for the same assignment given to individuals (see Figure 4).

On the positive side, as long as members appear to be motivated to get the same grade, being required to produce a group term paper gives members enough of a common goal that they are able to agree on a strategy for completing the assignment. Unfortunately, the same features that limit the Depth of Learning score for group term papers (independent/individual work, little member interaction and delayed feedback) clearly create overwhelming barriers to team development as well. In addition, members are well aware that the failure of any member of the group could force the rest to accept a low grade, engage in a last-minute attempt to salvage a disaster, or both, and, is likely to create outright hostility among group members. On balance, we would score group papers a 2 or 3 on Team Development and an overall LVS of 5 or 6 (see Figure 4).

Group term papers - a no-win assignment. If everything goes exactly right, a group term paper could have an overall LVS as high as a 9. However, unless instructors are willing to provide a tremendous amount of personal coaching and support for the groups, we strongly recommend against assigning group term papers under any circumstances for three reasons. First, a score of 9 is highly unlikely. Even when the group product is a good one, a score of 3 or 4 is much more realistic. Second, although unintended, the primary lesson that many students learn from group term papers (and other group assignments that have a low Team Development score on the LAI-Grid) is a very negative one. When things go wrong, students (and many faculty as 
well) blame the failure on either individual group members or on groups in general, even though the real problem is that the task of writing a term paper, by its very nature, is not appropriate for groups. As a result, many students naively conclude that groups are something to be avoided unless the sheer volume of work prevents you from doing the job yourself. Third, because the nature of the assignment inevitably puts better students at risk, sooner or later instructors who assign group term papers will be faced with either an academic appeal, a lawsuit or both. Some students will simply not tolerate getting a bad grade because of another student's lack of ability or willingness to do their part on a group assignment.

\section{Increasing the Impact of Assignments}

One of the key variables that affects the impact of every learning activity is the phrasing used to describe the parameters for the assignment. Even subtle changes can produce substantial differences in learning outcomes because of their impact on both Depth of Learning and Team Development. Further, the LAI-Grid allows instructors to predict the outcomes in advance so that they can select and/or design assignments that will produce the learning outcomes that they are striving to achieve.

Phrasing individual assignments to promote Depth of Learning. The degree to which an assignment can impact learning is dependent on the extent (intensity and number of occurrences) of elaborative rehearsal and, whether or not the assignment requires students to link information to a problem. The way in which an assignment is phrased affects both dimensions. For example, a marketing instructor may want students to understand the key variables that need to be considered in selecting a site upon which to locate new business. To achieve this goal the instructor might assign a brief individual paper to be based on data collected from a specific number of reference sources. Three alternative ways to state the assignment are shown in Figure 7.

In the example shown in Figure 7, the LVS of the first alternative would be lowest (around 3) and the LVS of the last alternative would be the highest (approaching 7) with alternative 2 somewhere in be- 


\section{Figure 7 \\ Alternatives for Assignment Phrasing}

1) "List the key business site selection factors and explain why each is important."

2) "Identify the single most important site selection factor for locating a business in (name a specific city about which students could gain access to data on each of the potentially important dimensions) and explain the rationale for your selection."

3) "Select what you think would be the ideal site to locate a new (name a specific business e.g. dry cleaning) in (name a specific city about which students have access to data on each of the potentially important dimensions) identify the single most important site selection factor that led to your decision and, be prepared to explain rationale for your decisions."

tween. This variation occurs because of differences in the extent to which students would be required to engage in elaborative rehearsal. "Making-a-list" assignments can be accomplished simply by extracting items from one source and recording them in another location. "Making-a-choice" assignments stimulate elaborative rehearsal because they require critically examining a list to make judgments about the relevance of each item in this particular situation. Further, "Making-a-specific-choice" assignments stimulate the highest level of elaborative rehearsal because they require students to compare and contrast the relative importance of a larger number of variables.

Group assignments provide a minimum of two additional opportunities to increase students' Depth of Knowledge. One opportunity is during discussions within the teams. The other opportunity occurs during subsequent class discussions between teams. Moreover, the phrasing used in team assignments also affects the learning that occurs during discussions both within and between teams and in exactly the same way as with individual assignments. For example, asking a team (or total class) to make a list of variables that should be considered in making business location decisions would result in a low-energy exchange in which every input would have virtually the same weight, irrespective of its actual perspicacity. By contrast, within the limits inherent in the maturity of the team, the task of agreeing on a single 
best location for a specific business in a specific town would produce an energetic and thoughtful discussion of the relative importance of the entire set of issues involved.

Phrasing assignments to promote Team Development. Makea-list assignments are not very effective for building teams because it dampens interactions both within and between teams. Listing possibilities tends to be a low energy team task for at least two reasons. One is that it focuses on quantity rather than quality. The other is that making a list seldom leads to a feeling of closure. The dampened interactions between teams occurs because the output (in this case, the resulting list) is both visually complex and likely to be quite similar across teams. Thus, the differences that teams might otherwise take pride in, are both obscured and diminished in significance by the sheer volume of data. By contrast, make-a-specific-choice assignments enhance Team Development by increasing the intensity of interactions both within and between teams. Struggling to make a specific choice increases both member understanding of and commitment to the output.

Multiplying benefits of "make-a-specific-choice" assignments. The value of make-a-specific-choice type assignments is even greater in a learning group context. Compared to make-a-list assignments, they both increase learning in each step of the process and set the stage for greater learning in the next. See Figure 8. For example, as long as members are working on the same task, making individual decisions on a single best location for a specific business in a specific town produces an ideal learning experience in subsequent discussions within their teams. Learning occurs because having to make an individual choice ensures that each member enters the discussion with a well-developed schema and any conflict between member choices is readily apparent. As a result, each team member is both intellectually prepared and motivated to engage in a reasoned and examination of the variables involved in making their choice.

Phrasing team assignments in make-a-specific-choice terms also produces two additional positive outcomes. One is that discussions within the teams naturally have the give-and-take character that causes students to engage in elaborative rehearsal. The other is that each team's choice is both readily comparable to the choices of other teams 


\section{Figure 8 \\ Impact of Assignment Phrasing}

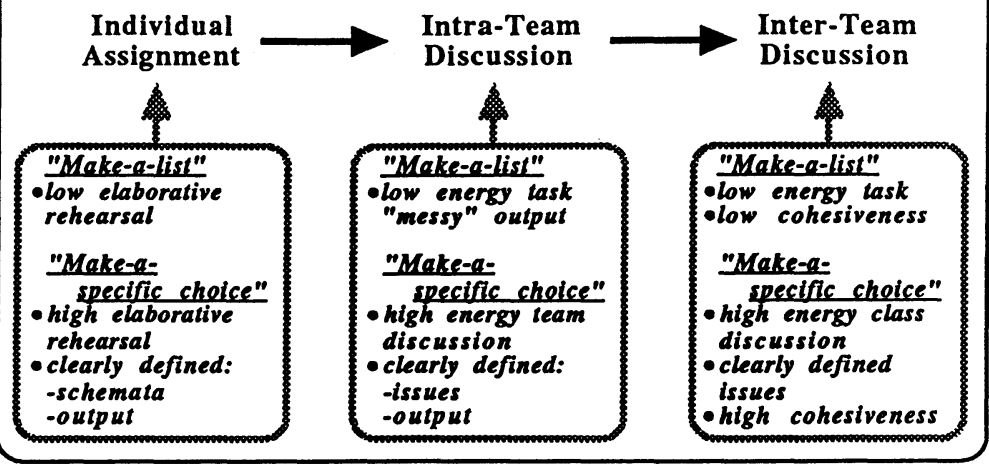

within the class and worthy of being defended. This, in turn, sets the stage for another round of productive give-and-take discussions between teams and, at the same time, promotes Team Development. As a result, the LVS of make-a-specific-choice team assignments is often 15 or above on the LAI-Grid.

\section{Summary: Learning Activities - Choices and Consequences}

Teaching is no different than any other profession in that choices bring consequences. In the same way that artists' choices of tools enhances or detracts from productivity, instructors' choices with respect to the use of class time have a great impact on their students' learning. Every activity affects learning in two ways. One is the direct impact that is associated with the extent to which the activity causes students to think about the concepts being taught. The other is the indirect impact (positive or negative) on the development of learning groups.

The indirect impact of learning activities is particularly important to instructors who want to do more than simply disseminate information. Except in very small classes, it is virtually impossible for the 
instructor to personally provide the timely and specific feedback required for the development of students' knowledge use and transfer skills. As a result, using group activities and assignments is essential to the achievement of the many faculty members' desired instructional objectives. However, activities and assignments must be insightfully designed. The natural consequence of ill-conceived group assignments is that they may produce only one positive effect, such as increased learning of a subset of the material, while producing three negative effects, such as, decreased learning of the remainder of the material, resentment from what is generally perceived to be an uneven sharing of the work load, and a residual student aversion group work.

On the other hand, by using insightfully designed in-class assignments, instructors can do far more than avoid problems with learning groups. They can virtually ensure that their students will master basic content and, at the same time, they can create a learning environment in which team members are able and willing to provide the quality of feedback to each other needed for the development of higher level cognitive skills. Further, these positive outcomes are highly predictable because, for most students, they are the natural response to effective in-class group assignments. Thus, students in well-managed learning teams increasingly become capable of completing the kind of difficult and complex tasks that are needed for the development of students' ability to use their knowledge to solve unstructured problems and in new situations and willing and able to take on the primary responsibility for providing the immediate feedback that enables them to learn from their experience.

\section{References}

Anderson, J. R. (1993). Problem solving and learning. American Psychologist, 48, 35-44.

Bargh J. A., \& Schul, Y. (1980). On the cognitive benefits of teaching. Journal of Educational Psychology, 74(5), 593-604.

Bloom, B. S. (1956). Taxonomy of educational objectives: The classification of educational goals. New York: David McKay.

Bloom, B. S., Madaus, J. F. \& Hastings, J. T. (1981). Evaluation to improve learning. New York: McGraw-Hill.

Bonwell, C. \& Eisen, J. A. (1991) Active learning: Creating excitement in the classroom. Washington, DC: The George Washington University. 
Bruning, R. H., Schraw, G. J, \& Ronning, R. R. (1994). Cognitive Psychology and instruction (2nd ed.). Englewood Cliffs, NJ: Prentice Hall.

Cottell, P., Millis, B. J. \& Engrave, R. W. (1996). Cooperative learning techniques and teaching notes: Financial accounting. Cincinnati, $\mathrm{OH}$ : Southwestern College.

Craik, F. L. M. \& Lockhart, R. S. (1986). CHARM is not enough: Comments on Eich's model of cued recall. Psychological Review, 93, 360-364.

Fiechtner, S. B. \& Davis, E. A. (1985). Why groups fail: A survey of student experiences with learning groups. The Organizational Behavior Teaching Review, 9(4), 58-73.

Glover, J. A. , Ronning, R. R. \& Bruning, R. H., (1990). Cognitive Psychology and instruction. Englewood Cliffs, NJ: Prentice Hall.

Kurfiss, J. G. (1988). Critical thinking: Theory, research, practice, and possibilities. Washington, DC: The George Washington University, School of Education and Human Development.

Mandler, J. M. (1984). Stories, scripts, and scenes: Aspects of schema theory. Hillsdale, NJ: Lawrence Erlbaum.

McKeown, M. G. \& Curtiss, M. E. (1987). The nature of vocabulary acquisition. Hillsdale, NJ: Lawrence Erlbaum.

Michaelsen, L. K. (1992). Team learning: A comprehensive approach for harnessing the poser of small groups in higher education. In D. H. Wulff \& J.D. Nyquist (Eds.) To Improve the Academy: Resources for Faculty, Instructional and Organizational Development, 1992. Stillwater, OK : New Forums.

Michaelsen, L. K. \& Black, R. H. (1994). Building learning teams: The key to harnessing the power of small groups in higher education. Collaborative Learning: A Sourcebook for Higher Education (2). State College, PA: National Center for Teaching, Learning and Assessment.

Michaelsen, L. K., Fink, L. D., \& Watson, W. E. (1994). Pre-instructional minitests: An efficient solution to covering content. Journal of Management Education, 18 (1), 32-44.

Michaelsen, L. K., Watson, W. E. \& Black, R. H. (1989). A realistic test of individual versus group consensus decision making. Journal of Applied Psychology, 74(5), 834-839.

Michaelsen, L. K., Watson, W. E., Cragin, J. P. \& Fink, L. D. (1982). Team learning: A potential solution to the problems of large classes. Exchange: The Organizational Behavior Teaching Journal, 7(1), 13-22.

Michaelsen, L. K., Watson, W. E. \& Schraeder, C. B. (1985). Informative testing: A practical approach for tutoring with groups. Organizational Behavior Teaching Review, 9(4), 18-33.

Norman, G.R., \& Schmidt, H. G. (1992). The psychological basis of problem-based learning: A review of the evidence. Academic Medicine, 67(9), 557-565.

Nungester, R. J. \& Duchastel, P. C. (1982). Testing versus review: Effects on retention. Journal of Applied Psychology, 74(1), 18-22. 
Shaw, M. E. (1981). Group dynamics: The psychology of small group behavior. New York: McGraw-Hill.

Stepien, W., \& Gallagher, S. (1993). Problem-Based Learning: As authentic as it gets. Educational Leadership, 25-28.

Slavin, R.E., \& Karweit, N. L. (1981). Cognitive and affective outcomes of an intensive student team learning experience. Journal of Experimental Education, 50(1), 29-35.

Vygotsky, L. S. (1978). Mind in society: The development of higher psychological Processes. Boston: Harvard University.

Watson, W. E., Kumar, K. \& Michaelsen, L. K. (1993). Cultural diversity's impact on group process and performance: Comparing culturally homogeneous and culturally diverse task groups. The Academy of Management Journal. 36(3), 590-602.

Watson, W. E., Michaelsen, L. K. \& Sharp, W. (1991). Member competence, group interaction and group decision-making: A longitudinal study. Journal of Applied Psychology, 76, 801-809.

Contact:

Larry K. Michaelsen

Division of Management

University of Oklahoma

206 Adams Hall

Norman, OK 73019-0450 USA

(405) 325-5692

(405) 325-1957 FAX

lmichael@uoknor.edu

Larry K. Michaelsen is David Ross Boyd Professor of Management at the University of Oklahoma and former editor of the Journal of Management Education. His primary research interests are the dynamics of group problem-solving and the use of group-based activities for increasing students' higher level learning and group problem solving skills. He has also received numerous awards for his teaching and for his pioneering work with Team Learning, a comprehensive small-group based instructional process.

Robert H. Black is a private business owner and has been an adjunct professor of statistics and information systems for 22 years. His experience as the owner of a computer software company and as a financial consultant provide a basis for designing effective hands-on assignments for student teams. He has published a number of articles in academic journals.

L. Dee Fink has served as Director of the Instructional Development Program at the University of Oklahoma since 1979. His primary interests are evaluation of classroom instruction and developing methods for increasing students' higher level learning. 